\title{
Chronic low back pain
}

\section{Rania Zeitoun ${ }^{1}$ (D) $\cdot$ Petra Balogh ${ }^{2} \cdot$ Amir Amiri $^{3} \cdot$ Alex Gibson $^{3} \cdot$ Asif Saifuddin $^{4}$}

Published online: 10 September 2019

(C) ISS 2019

\section{History}

A 46-year-old female was referred with a 2-year history of worsening low back pain, with occasional night pain and difficulty walking. On examination she had mild discomfort on palpation over her lower lumbar spine Figs. 1, 2, 3 and 4.

The diagnosis can be found at https://doi.org/10.1007/s00256-01903311-z

\section{Rania Zeitoun}

raniazeitoun@gmail.com

1 Imaging Department, Kasr Al-Ainy Faculty of Medicine, Cairo University, Giza, Egypt

2 Histopathology department, Royal National Orthopaedic Hospital NHS Trust, Stanmore, UK

3 Spinal Surgery Department, Royal National Orthopaedic Hospital NHS Trust, Stanmore, UK

4 Imaging Department, Royal National Orthopaedic Hospital NHS Trust, Stanmore, UK

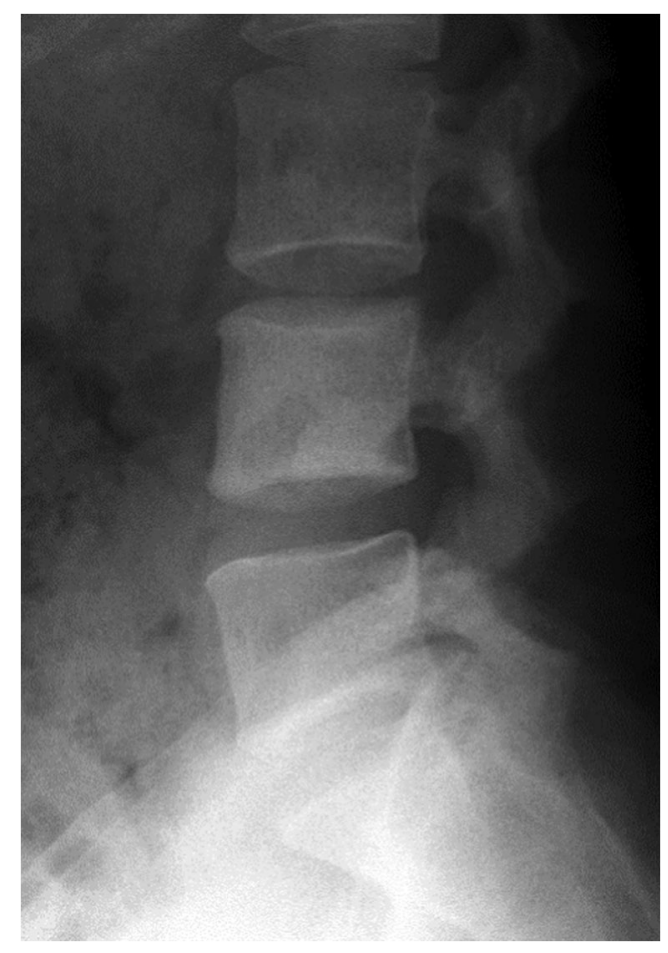

Fig. 1 Lateral radiograph of the lumbar spine 
Fig. 2 a Axial and b sagittal CT
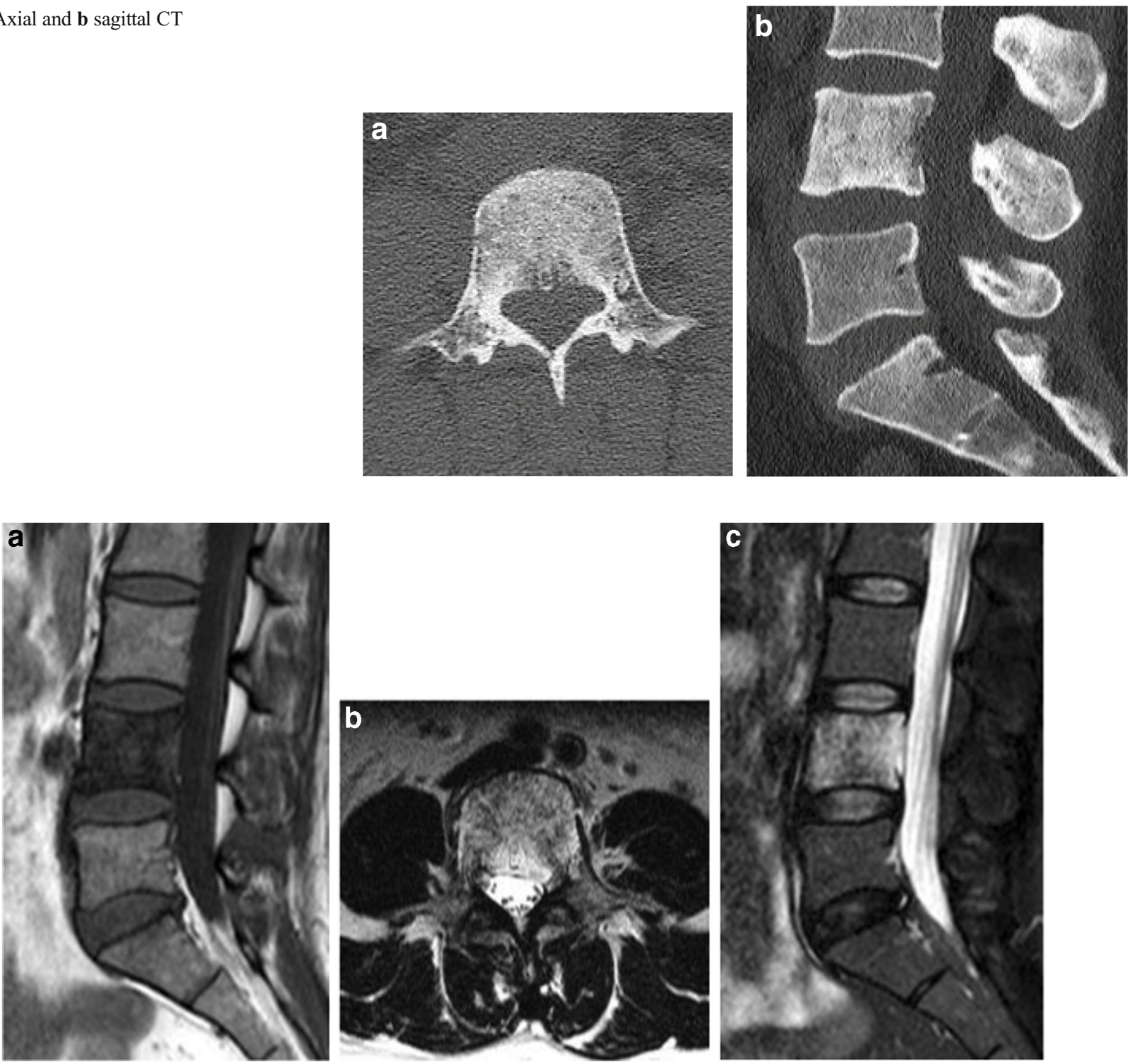

Fig. 3 a Sagittal T1W SE MR image b axial T2W FSE and $\mathbf{c}$ sagittal STIR MR images
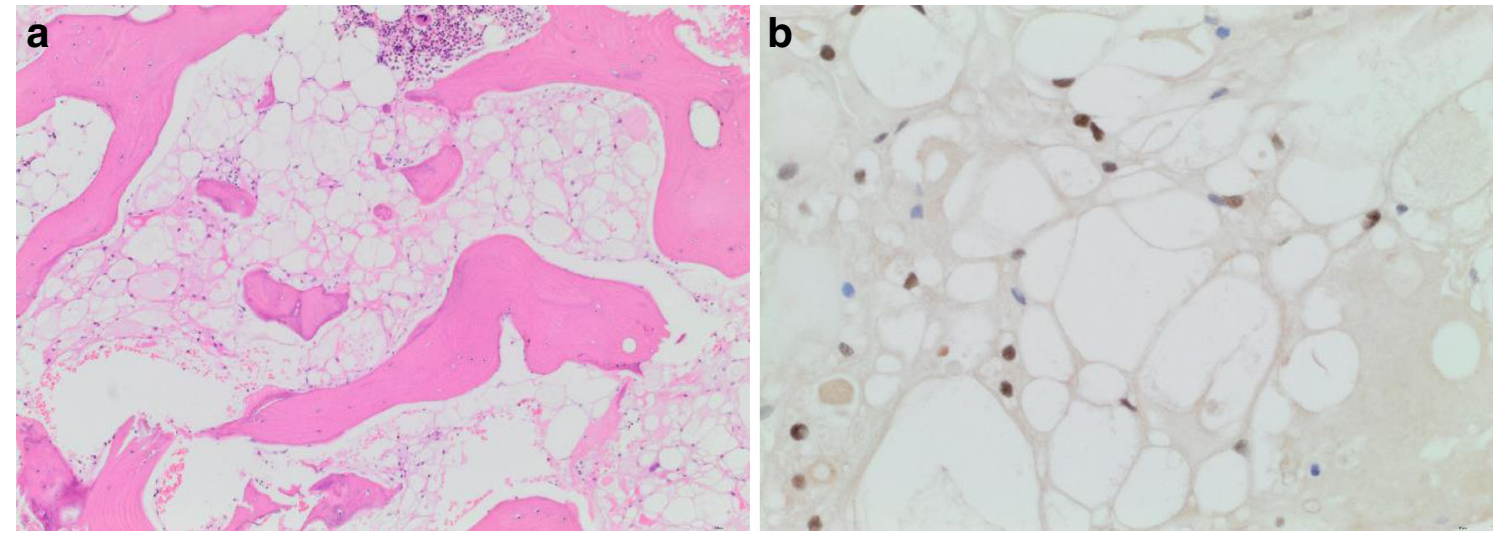

Fig. 4 a Microphotograph (H\&E, $5 \times$ magnification). b Nuclear immunostain positive for brachyury 
Acknowledgements The authors would like to acknowledge the help of Dr. RT, Consultant Histopathologist for providing the histology images.
Publisher's note Springer Nature remains neutral with regard to jurisdictional claims in published maps and institutional affiliations.

Authors Contribution All authors have made substantial contributions to all four categories established by the International Committee of Medical Journal Editors. 